\title{
Prevalence of Ectoparasites and Its Identification in Captive Wild Birds
}

\author{
K. Saranya ${ }^{1 *}$, S. Prathaban ${ }^{2}$, K. Senthilkumar ${ }^{3}$, A. Srithar ${ }^{3}$ and S. Gomathinayagam ${ }^{4}$ \\ ${ }^{1}$ Aavin, Salem and Namkkal District Cooperative Milk Union Ltd, \\ Salem-636115 India \\ ${ }^{2}$ Department of Wildlife Science, ${ }^{3}$ Department of Veterinary Microbiology, ${ }^{4}$ Department of \\ Veterinary Parasitology, Madras Veterinary College, Chennai-07, India \\ *Corresponding author
}

\section{A B S T R A C T}

\section{Keywords}

Ectoparasites, Captive Wild Birds, Psittaciformes, Columbiformes

Article Info

Accepted: 08 July 2018 Available Online: 10 August 2018
The present study was undertaken to determine the prevalence of ectoparasite in captive wild birds. Fallen feathers and individual bird examination was conducted for identification of mite, lice and fly in Psittaciformes and columbiformes bird from Avian and Exotic pet Unit (AEPU) (OP), Teaching veterinary clinical complex, Madras veterinary college, Chennai, University Research farm (URF), Tamilnadu Veterinary and Animal sciences University, Madhavaram, Chennai, Arignar Anna Zoological Park (AAZP)-Vandalur, Chennai, Private and Pet Shops in and around Chennai. Columbicola sp, Menocanthus sp, Anaticola sp and Pseudolynchia sp were identified in AEPU and URF.

\section{Introduction}

External parasites were relatively rare in pet birds, especially the caged birds (Turner, 1992). Alderton (1980) stated that parasitic infestations were unlikely to occur in birds housed inside, because they were out of contact with wild birds. The examination of feather base and distal parts of feathers for the presence of mites. Fowler (1986) suggested the examination of skin as well as the feathers for ruling out the evidences of ectoparasites.
Prathiba et al., (2015) documented the feather mites may be found on pet birds, most often psittacines and are most commonly found on immunocompromised birds. Avian lice belong to the order Mallophaga (the chewing or biting lice) and are known for their rigid host specificity as stated by Alderton (1980). Foronda et al., (2004) documented prevalence of Columbicola columbae. Singh et al., (2010) found out the pigeon slender louse (Columbicola columbae) in pigeon lives in barbules of feathers. Choi et al., (2016) 
encountered Anaticola anseries in goose. Girisgin et al., (2013) documented the chewing lice (Ischnocera, Amblycera) are permanent ectoparasites primarily of bird species and they feed on feathers and skin scales.

Macchioni et al., (2005) reported that pigeon fly were common in many areas of the world and blood smears obtained from the fly infected pigeon were positive for Haemoproteus columbae. Pirali-Khodadad et al., (2016) stated that Pseudolynchia canariensis, a Hibboboscidae fly was important ectoparasites of pigeons.

\section{Materials and Methods}

\section{Study areas}

This study was undertaken in Psittacine birds from Avian and Exotic Pet Unit (AEPU) (OP) of Madras Veterinary college, Guindy Children's Park, University Research Farm (URF) and private and pet places in and around Chennai from October 2016 to July 2017

\section{Study period}

The total period of study was approximately ten months from October 2016 to July 2017

\section{Place of sample collection}

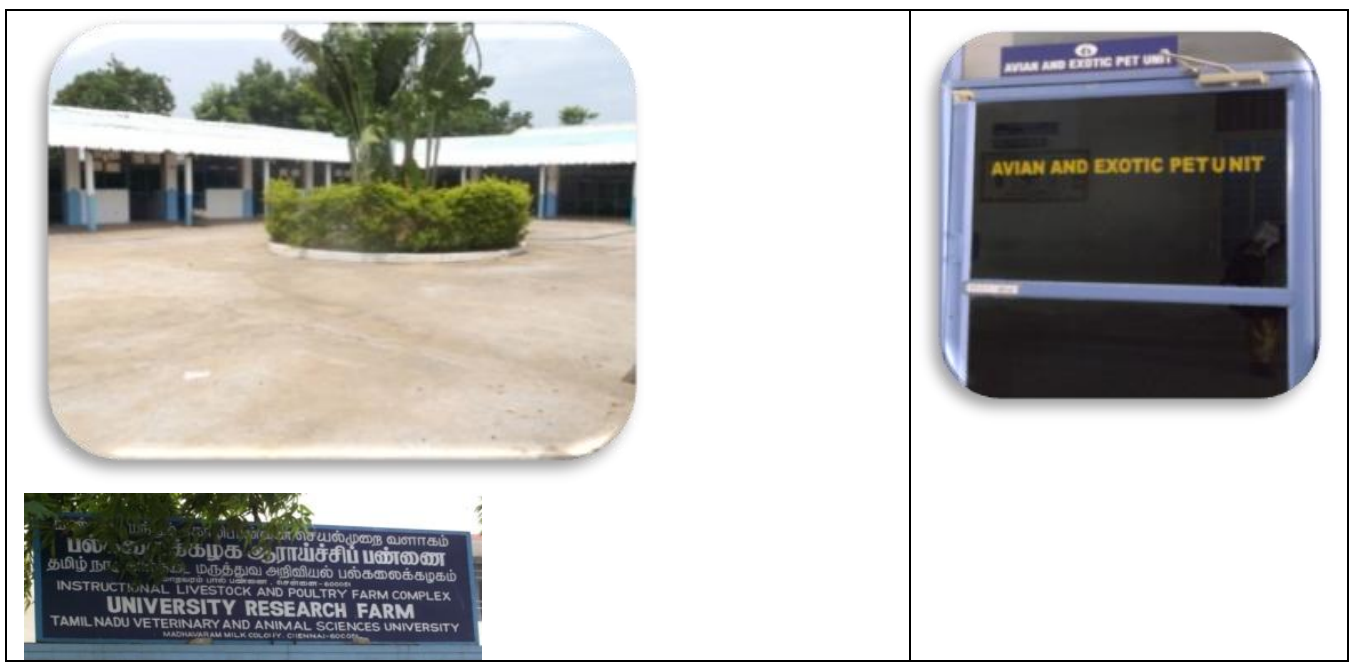

Study was conducted in the following Captive wild avifauna in Tamilnadu

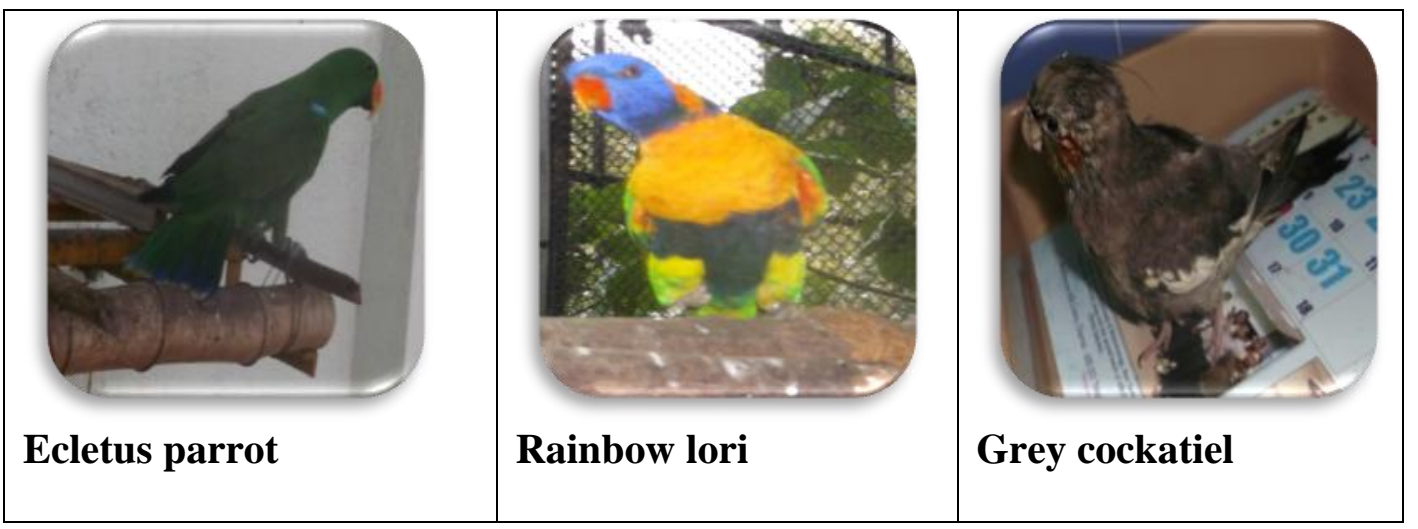




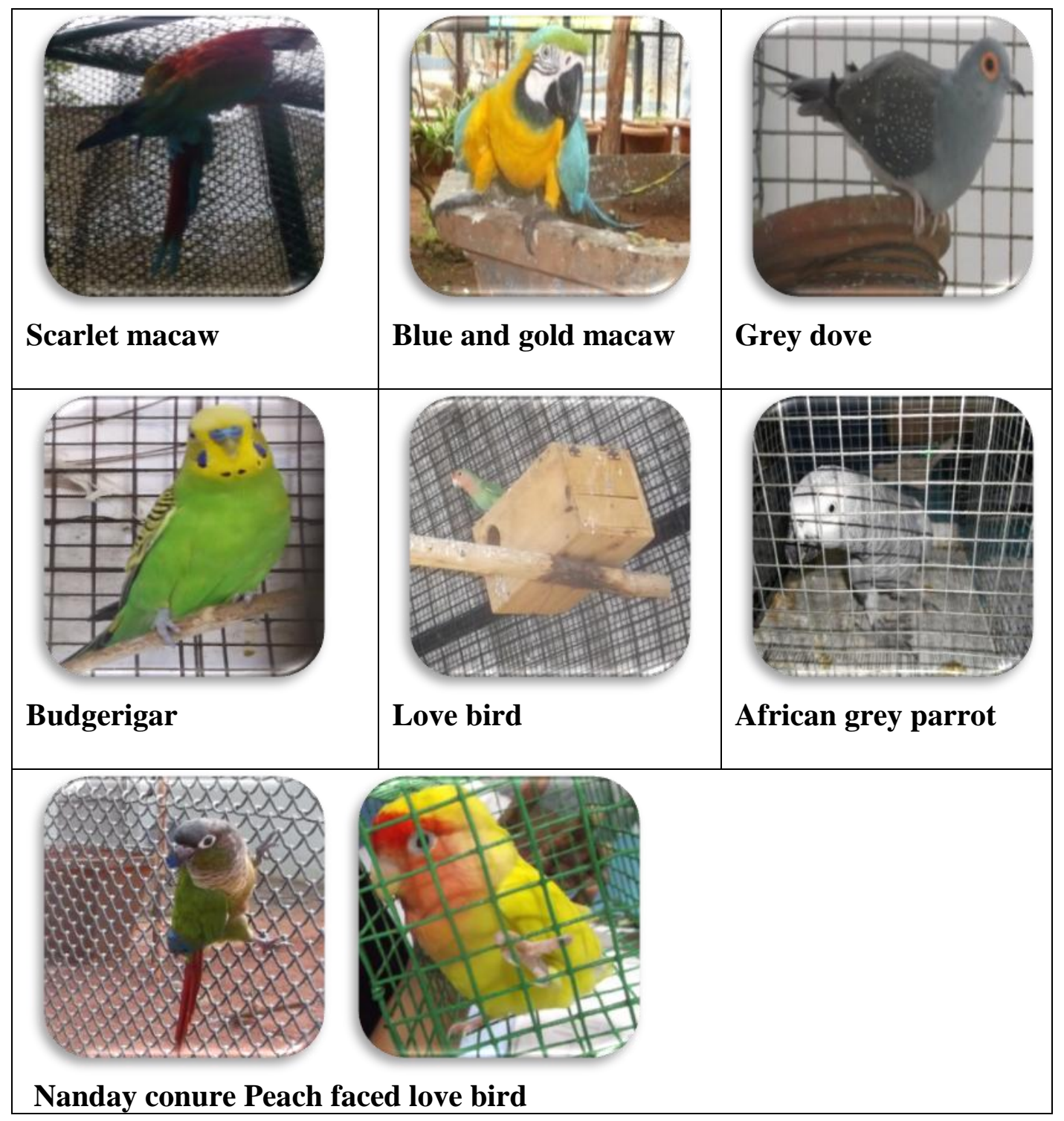

\section{Methods of examination}

\section{Collection and preservation of feathers}

The fallen feathers were collected from captive areas in Avian and Exotic Pet Unit (AEPU), University Research Farm (URF), Aringar Anna Zoological Park (AAZP) and Private and pet shops in and around Chennai were stored in air tight containers with 10 percent formalin for examination of evidence of ectoparasite. The containers were sealed with para film coverage, labeled and stored properly.

\section{Analysis of feathers}

The feathers from captive wild birds were grossly examined for the presence of any ticks. The feathers were cut into pieces and were placed in $10 \mathrm{ml}$ of $10 \%$ sodium hydroxide solution. It was boiled for 5 to 10 minutes.

The test tube was cooled in running tap water and was centrifuged at $2000 \mathrm{rpm}$ for 5 minutes. The supernatant was decanted and a small quantity of sediment was placed on a microscopic slide using Pasteur pipette and 
bulb. Subsequently, the cover slip was duly placed over the drop of sediment and slide was examined microscopically under both low and high power objectives for the presence of mites.

\section{Visual examination}

Ectoparasitic loads in birds can be quantified by searching the entire skin and plumage and deflect the feathers with forceps. Lice infected feathers were cut with scissor and examined under dissecting microscope.

\section{Ectoparasite collection technique (Visual examination)}

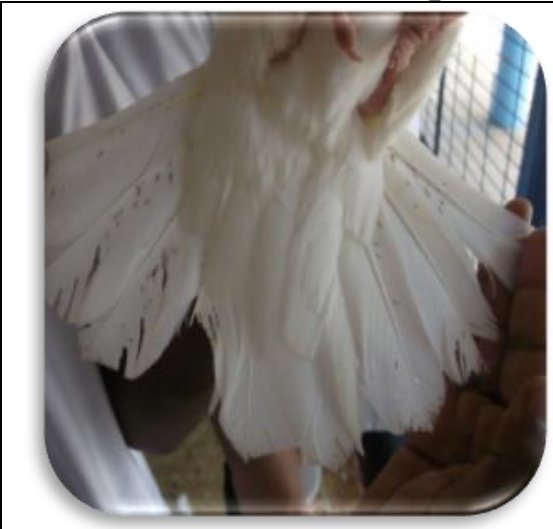

1.Examination of Tail feathers

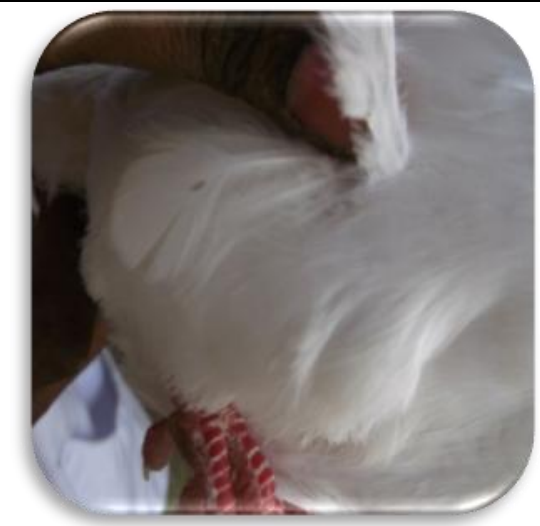

2.Examination of Body feathers
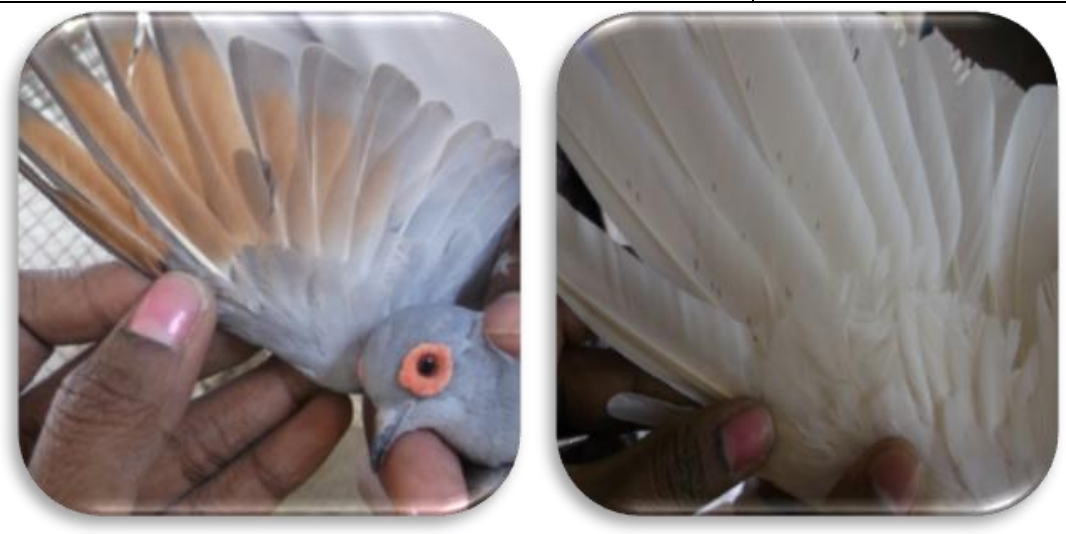

3. Examination of wing feathers

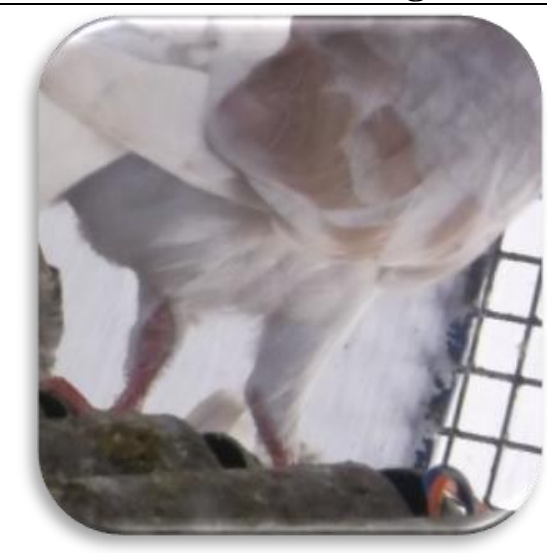

4. Examination of thigh

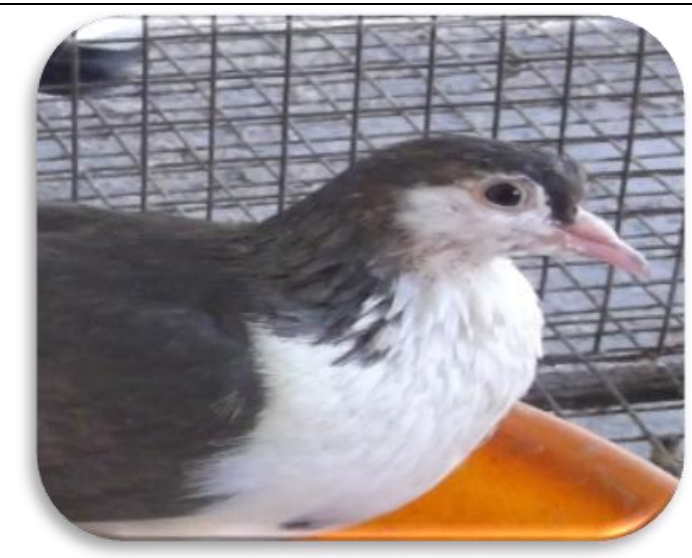

5. Examination of head and neck 
Processing and identification of Ectoparasites

The lice were boiled in 10 per cent sodium hydroxide $(\mathrm{NaOH})$ for 10 minutes, followed by cooling in running tap water. Then the lice were dehydrated in ascending grades of alcohol stock, $70 \%$ alcohol for 5 minutes, 90 $\%$ alcohol and absolute alcohol for 5 minutes each. Finally, lice were placed in Xylene for 10 minutes for clearing and the lice were mounted on slides by use of DPX mountant. The lice was examined microscopically and species were identified, using the information furnished by Soulsby (1982) and Walter and Francis (1984).

\section{Statistical analysis}

Analysis of data was carried out scientifically and statistical analysis (Chi-square test) was done as by SPSS soft ware.

\section{Results and Discussion}

Ectoparasitic incidence of captive wild avifauna in AEPU and URF

Total of 96 feathers were collected from AEPU, URF, AAZP and private and pet shops. No ectoparasites were founds in birds at AAZP and Private and pet shops. Feathers from AEPU $(\mathrm{n}=56)$ found to be positive for Colimbicola sp, Menocanthus sp, Pseudolynchia sp and Anaticola sp. Further, $7.14 \%(\mathrm{n}=4)$ of samples were positive for Columbicola sp, 5.35\% ( $\mathrm{n}=3)$ of samples were positive for Menocanthus sp, $1.78 \%(\mathrm{n}=2)$ of samples positive for Pseudolynchia sp, 1.78\% $(\mathrm{n}=1)$ of samples reveled positive for Anaticola sp (Plate-1). The values are presented in Table 1. Overall value of ectoparasitic infection in case of AEPU was $17.85 \% \quad(\mathrm{n}=10) \quad$ (Figure 1). Similarly, 20 feathers were collected from URF and found to be positive for Columbicola sp and
Menocanthus sp. Further, $40 \% \quad(\mathrm{n}=8)$ of samples revealed positive for Columbicola sp, $35 \% \quad(\mathrm{n}=7)$ of samples were positive for Menocanthus sp (Plate-1). The values are presented in Table 1. Overall value of ectoparasitic infection in case of URF was $75 \%(\mathrm{n}=15)$ (Figure 1).

Evidence of ectoparasitic incidence in captive birds

Lice Menacanthus sp and columbicola sp encountered in AEPU, URF and was in agreement with key documented by Musa et al., (2012) who opined that ectoparasites Columbicola sp (50\%) showed highest prevalence while, Menocanthus sp had highest intensity (20.25 3.5 ) and were found in pigeons. Dranzoa et al., (1999) and foronda et al., (2004) also found $94.1 \%$ prevalence and $100 \%$ prevalence of Columbicola columbae in Uganda and Tneriffe, respectively.

Anaticola sp was encountered in goose in AEPU unit during study period. This finding was similar to key provided by Choi et al., (2016).

Lice Columbicola columbae was encountered in feathers was in aggrement with key provided by Singh et al., (2010) who encountered the Columbicola columbae, the pigeon slender louse mostly feeds upon barbules of feathers but in addition to this it also feeds upon skin scruf, epidermal scales, sheaths of growing feathers, pellicle of skin etc. the louse prefers the wing and tail feathers for oviposition.

Infestation of cloumbiformes with pigeon fly has been reported from many areas of the world and blood smears obtained from the pigeon which is infected with pigeon fly shows positive for Haemoproteus columbae. The pigeon fly also transmits a pathogenic protozoa by Macchioni et al., (2005). 
Table.1 Overall incidence of ectoparasitic infestation in wild birds at AEPU and URF

\begin{tabular}{|c|l|c|c|}
\hline Sl.No & \multicolumn{1}{|c|}{ Parasites } & $\begin{array}{c}\text { AEPU } \\
(\mathbf{n = 5 6})\end{array}$ & $\begin{array}{c}\text { URF } \\
(\mathbf{n = 2 0})\end{array}$ \\
\hline 1 & Columbicola $\mathrm{sp}$ & $4(7.14 \%)$ & $8(40 \%)$ \\
\hline 2 & Menocanthus $\mathrm{sp}$ & $3(5.35 \%)$ & $7(35 \%)$ \\
\hline 3 & Pseudolynchia $\mathrm{sp}$ & $2(3.57 \%)$ & 0 \\
\hline 4 & Anaticola $\mathrm{sp} \quad 1(1.78 \%)$ & 0 \\
\hline & \multicolumn{1}{|c|}{ Total } & $10(17.85 \%)$ & $15(75 \%)$ \\
\hline
\end{tabular}

Table.2 Ectoparasitic incidence in captive wild avian at URF, AEPU - CHI-square test

\begin{tabular}{|c|c|c|c|c|}
\hline Sl.No & Avian units & Positive & Negative & Chi square test $\left(\boldsymbol{X}^{2}\right)$ \\
\hline 1 & URF $(\mathrm{n}=20)$ & 15 & 5 & \multirow{2}{*}{$21.79^{* * *}$} \\
\hline 2 & AEPU $(\mathrm{n}=56)$ & 10 & 46 & \\
\hline
\end{tabular}
$X^{2}=21.79^{* * *} \mathbf{P} \leq 0.01$.

** significant

Statistical analysis revealed highly significant differences of ectoparasites encountered in URF, AAZP (Table 2).

Plate.1 Ecoparasites - Lice

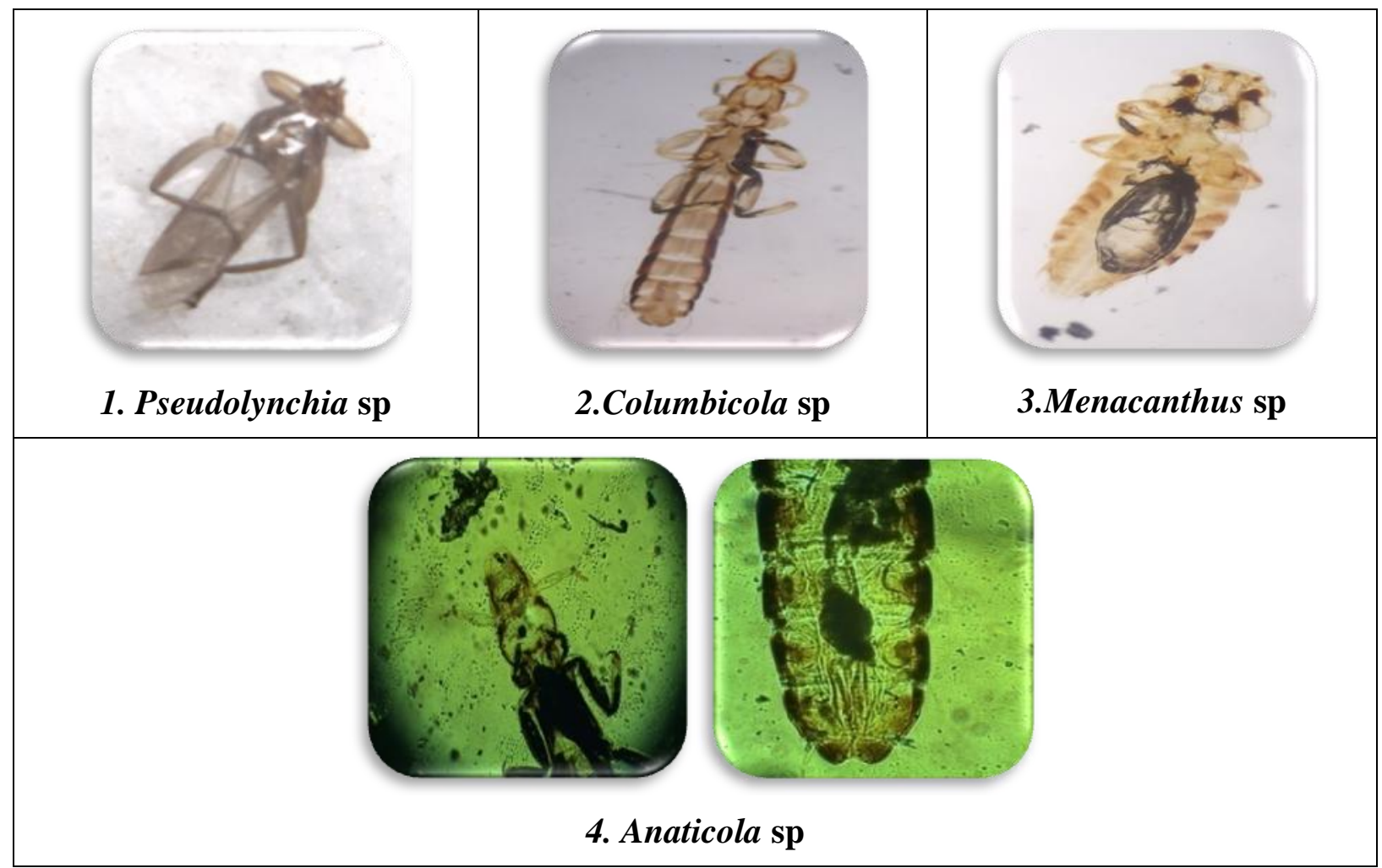


Fig.1 Overall Place wise ectoparasitic incidence in AEPU and URF

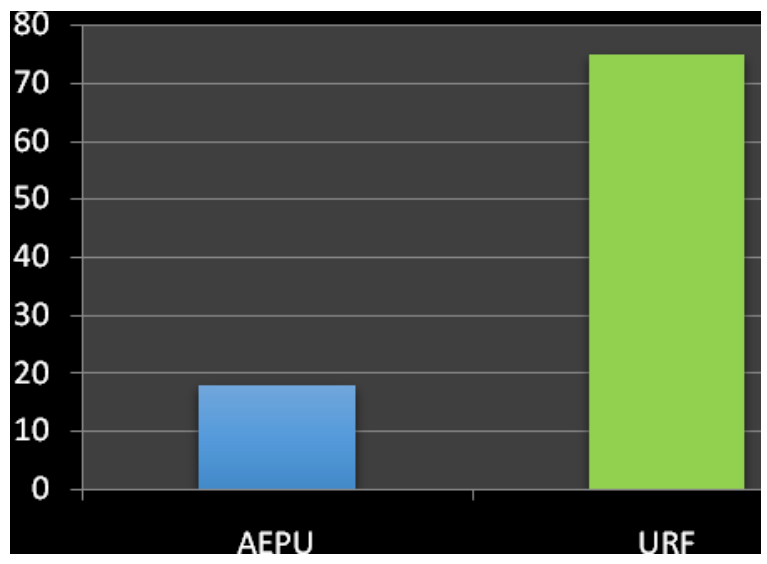

Pseudolynchia canariensis was encountered in AEPU unit in pigeon. This was in agreement with the report presented by Pirali et al., (2016) who stated that Pseudolynchia canariensis a hibboboscidae fly is one of the important ectoparasites of pigeons and is responsible for transmission of pathogen to birds.

Statistical analysis using Chi-Square test revealed highly significant difference of ectoparasitic incidence (Table 2) between URF and AEPU. There is higher incidence of ecto parasite in URF were compared to that of AEPU. It is mainly due to the reason that there were 20 number of pet birds in a single enclosure in URF where in there was high chance of infection between the pet owners rearing a pair of pet birds only where infection is minimized.

\section{Management measures}

The findings made in the study pertaining to ectoparasitic fauna encountered in the wing, tail, body feathers from Psittacine group of birds. Ectoparasite such as the Menocanthus $\mathrm{sp}$ and Columbicola sp, Anaticola sp was documented in AEPU and URF. Ectoparasite infected birds should be dusted with "Dry-die 67 " is a fluffy white amorphous silica aerogel powder, it is strong positive charge and its minute particle size cause it to adhere to the bodies of ectoparasites. This method used for treatment of ectoparasite infected birds, by this way we can collect ectoparasites. The dust is fast acting, and has additional property of irritating the parasites so that they release their grip on the host and may be easily dislodged. This powder is chemically inert and is non toxic to vertebrates (Robert, 1966). Johnson Rid mite insect powder which contains $0.1 \%$ pyrethrin and $0.8 \%$ piperynyl butoxide. This product available in market as "Scalex mite and lice spray for birds". Pyrethrin is derived from pyrethrum, a natural biodegradable insecticide extracted from flowers of Chrysanthemums. Pyrethrum and is derivatives are "fast knock down, slow killing" insecticides that are completely safe for use on birds and mammals. "Scalex spray" was highly effective against ectoparasite infected birds according to authors furnished above and collect ectoparasite by this method. (casida 1973, jackson1985). Piperonyl butoxide is a synergist that improves the efficiency of Pyrethrin. The Piperonyl butoxide+ Pyrethrin mixture has no effect on growth or survival of nestling or adult birds (Clayton and Tompkins 1995).

\section{References}

Alderton, D., 1980. Guide to cage birds. Saiga publishing Co. Ltd., Surrey, England. 
Pp. 63-76.

Casida, J.E. 1973. Pyrethrum, the natural insecticide. Academic Press, New York.

Choi, C. Y., J. Y. Takekawa, D. J. Prosser, L. M. Smith, C. R. Ely, A. D. Fox, and X. Xiao, (2016). Chewing Lice of Swan Geese (Anser cygnoides): New Host-Parasite Associations. The Korean Journal of parasitology, 54(5):685.

Clayton, D.H. and D.M. Tompkins, 1995.Comparative effects of mites and lice on the reproductive success of Rock Doves (Columba livia). Parasitology, 110:195-206.

Dranzoa, C., M. Ocaido and P. Katete 1999. The ecto-, gastro-intestinal and haemo parasites of live pigeons (Columba livia) in Kampala, Uganda.Avian Pathology., 28: 119-124.

Foronda, P., J.A. Rivera-Medina, E. Fiqueruela, N. Abreu and J.C. Casonova, 2004. Parasites of Columba livia (Aves: Columbiformes) in Tenerife (Canary Islands) and their role in the conservation biology of the laurel pigeons. Parasite, 11(3): 311116.

Fowler,M.E, 1986. Zoo and wild animal medicine. $2^{\text {nd }}$ Edn. W.B. Saunders Company. $2^{\text {nd }}$ edn, Philadelphia.

Girisgin, A. O., B. Dik and O. Girisgin, 2013. Chewing lice (Phthiraptera) species of wild birds in northwestern Turkey with a new host record. International Journal for Parasitology: Parasites and Wildlife, 2:217-221

Jackson, J.A., 1985. On the control of parasites in nest boxes and the use of pesticides near birds. Sialia, 7: 17-25

Macchioni, F., M. Magi, F. Mancianti and S. Perrucci, 2005. Phoretic association of mites and Mallophaga with the Pigeon fly Pseudolynchia canariensis. Parasite, 12(3): 277-279.

Musa, S., S. D Afroz and H. Khanum, 2012.Occurence of ecto-and endo parasites in pigeon (Columba livia). University Journal of Zoology, Rajshahi University, 30: 3-75.

Pirali-Kheirabadi, K., Dehghani-Samani, A., Ahmadi-Baberi, N., and Najafzadeh, V. (2016). A first report of infestation by Pseudolynchia canariensis in a herd of pigeons in Shahrekord (Southwest of Iran). Journal of Arthropod-Borne diseases, 10(3): 424.

Prathipa, A., M. G. Jayathangaraj, S. Gomathinayagam, and A. Thangavelu, 2013. Feather Mites of Psittacine Birds. Inter J Vet Sci, 4(1): 30-32

Robert C. Dalgleish, 1966. An improved technique for collecting bird ectoparasite, Turtox News, 4(12).

Singh, S. K., K. Arya, S. Singh and V. Khan, 2010. Feeding and reproductive behavior of pigeon slender louse, Columbicola columbae (Phthiraptera, Insecta, Ischnocera). J. Appl. Natu. Sci, 2(1): 126-133

Turner,W.T., 1992. Skin, feathers, beak, cere and uropygial gland. In: BSAVA Manual of parrots, budgerigars and other psittacine birds. Ed Price, C.J., BSAVA Kingsley House, Church Lane, Gluocestershire. Pp 103-109

\section{How to cite this article:}

Saranya, K., Prathaban, S., Senthilkumar, K., Srithar, A. and Gomathinayagam, S. 2018. Prevalence of Ectoparasites and Its Identification in Captive Wild Birds. Int.J.Curr.Microbiol.App.Sci. 7(08): 1093-1100. doi: https://doi.org/10.20546/ijcmas.2018.708.124 